\title{
Electrophysiologic Effects of Disopyramide Phosphate on Reentrant Ventricular Arrhythmia in Conscious Dogs After
}

\section{Myocardial Infarction}

EUGENE PATTERSON

JOHN K. GIBSON, PhD*

BENEDICT R. LUCCHESI, PhD, MD

Ann Arbor, Michigan
From the Department of Pharmacology and the Upjohn Center for Clinical Pharmacology, The University of Michigan Medical School, Ann Arbor, Michigan. This study was supported by U.S. Public Health Service Grant HL 05806-20 from the National Heart, Lung, and Blood Institute, National Institutes of Health, Bethesda, Maryland. Manuscript received November 20, 1980; revised manuscript received May 13, 1980; accepted May 16, 1980.

" Research Fellow of the Michigan Heart Association, Detroit, Michigan.

Address for reprints: Benedict R. Lucchesi, PhD, MD, Department of Pharmacology, M6322 Medical Science Building I, The University of Michigan Medical School, Ann Arbor, Michigan 48109.
The electrophysiologic actions of disopyramide phosphate on reentrant ventricular tachycardia Induced by premature ventrlcular stimuli were evaluated in conscious dogs 2 to 4 days after myocardial infarction. Disopyramide was administered as a series of intravenous infusions to obtain successive steady state plasma disopyramide concentrations of $1.02 \pm$ $0.02,2.05 \pm 0.08,3.94 \pm 0.09$ and $7.69 \pm 0.18 \mu \mathrm{g} / \mathrm{ml}$ (mean values \pm standard error of the mean). Disopyramide plasma concentrations of 1.02 $\pm 0.02 \mu \mathrm{g} / \mathrm{ml}$ produced an increase in the rate and duration of ventricular tachycardia as well as in the interval during which premature ventricular stimull produced ventricular tachycardia. The effectlve refractory period of normal myocardium was decreased and conduction (activation time) was improved in ischemic myocardium. Increasing steady state plasma disopyramide concentrations slowed the rate of ventricular tachycardia without decreasing its duration. Slowing of the rate of tachycardia occurred simultaneously with a depression of conduction in normal and ischemic myocardium and an increase in ventricular refractoriness. Induction of ventricular tachycardia was prevented only at steady state plasma disopyramide concentrations of $7.69 \pm 0.18 \mu \mathrm{g} / \mathrm{ml}$. The results of this study suggest that subtherapeutic plasma concentrations of disopyramide may facilitate the development of reentrant ventricular arrhythmia in the electrically unstable heart. Ventricular tachycardia or fibrillation, or both, may be prevented only by plasma disopyramide concentrations that are in excess of the normal therapeutic range of 2 to 4 $\mu \mathrm{g} / \mathrm{ml}$.

Sudden death in patients with coronary artery disease results from severe disturbances of cardiac impulse formation or conduction that most often lead to ventricular fibrillation. Continuous electrical instability of the ischemic heart has been suggested as the primary factor leading to cardiac rhythm disturbances and can be exposed by the introduction of a critically timed premature ventricular stimulus that will initiate sustained ventricular tachycardia or ventricular fibrillation, or both. ${ }^{1-5}$

Studies of drugs that will prevent reentrant ventricular arrhythmia have been extensive in recent years, but have been hampered by the lack of a suitable animal model capable of identifying pharmacologic agents with the ability to reduce the incidence of ventricular fibrillation in the chronically ischemic heart. In most animal models used in the study of antiarrhythmic drugs, myocardial ischemia is created by acute coronary arterial ligation. Although this procedure will lead to ventricular fibrillation in a large proportion of the trials, the electrical events do not simulate the chronic electrical instability associated with sudden coronary death. ${ }^{6}$ In addition, ventricular tachycardia present 24 to 48 hours after experimental coronary arterial occlusion rarely culminates in ventricular fibrillation and is believed to be due to enhanced automa- 
ticity in Purkinje fibers. ${ }^{6,7}$ Recently, it was demonstrated that a critically timed electrically induced premature ventricular stimulus could initiate reentrant ventricular tachyarrythmia and ventricular fibrillation in dogs 2 to 9 days after acute myocardial infarction. This reentrant electrical activity also simulated that observed in patients in whom reentrant rhythms could be induced by programmed electrical stimulation of the heart. , $^{8}$

This study was undertaken for the purpose of evaluating the ability of disopyramide phosphate to prevent reentrant arrhythmia resulting from programmed electrical stimulation in the presence of chronic myocardial ischemia. The electrophysiologic effects of disopyramide phosphate were evaluated in relation to drug plasma concentrations. The results of these studies in the conscious dog with experimentally induced chronic myocardial ischemia demonstrate that disopyramide in clinically recommended plasma concentrations ( 2 to $4 \mu \mathrm{g} / \mathrm{ml}$ ) is unlikely to be beneficial in preventing reentrant ventricular tachyarrhythmia; this prevention can only be accomplished with plasma concentrations in excess of $4 \mu \mathrm{g} / \mathrm{ml}$.

\section{Methods}

Animal preparation: Male mongrel dogs weighing between 14.2 and $18.0 \mathrm{~kg}$ were anesthetized with intravenous sodium pentobarbital, $30 \mathrm{mg} / \mathrm{kg}$ body weight. Each animal was intubated with a cuffed endotracheal tube and ventilated with room air using a Harvard respirator. With use of aseptic techniques, sterile catheters were implanted in the left common carotid artery and left external jugular vein and passed subcutaneously to the surface through an incision in the back of the neck. A left thoracotomy was performed in the fourth intercostal space and the heart was suspended in a pericardial cradle. A $5 \mathrm{~mm}$ section of the left anterior descending coronary artery was dissected free from the surrounding myocardium at the tip of the left atrial appendage. A length of suture was passed around the artery and a 20 gauge needle, then securely tied and the needle withdrawn. Left anterior descending coronary arterial flow was monitored using an electromagnetic flow probe (Carolina Medical Electronics) before and after stenosis to ensure that coronary flow at rest was undisturbed. Silastic tubing was used to occlude coronary flow for a period of 90 minutes and then flow was allowed to return through the stenosed artery. Lidocaine hydrochloride, $5 \mathrm{mg} / \mathrm{kg}$ intravenously followed by $5 \mathrm{mg} / \mathrm{kg}$ intramuscularly, was given to those animals manifesting severe ventricular arrhythmia on reinstitution of coronary flow.

Electrical placements: A bipolar electrode was sewn onto the surface of the left atrial appendage. A second bipolar plunge electrode (28 gauge stainless steel, 5 to $7 \mathrm{~mm}$ in length) was placed on the right ventricular outflow tract with the exposed electrode tips placed in the interventricular septum.

Bipolar composite electrodes were placed on the epicardial surface of the left ventricle. One bipolar composite electrode was placed over normal myocardium and the second was placed over ischemic and infarcted myocardium. Correct placement of the hipolar composite electrodes was established at autopsy. The electrode wires were exited through the chest and passed subcutaneously to the back of the neck. The chest was closed in layers and procaine penicillin G, 1.2 million units, was administered intramuscularly.

Electrophysiologic studies: Forty-eight hours after myocardial infarction, the animals were conscious and resting comfortably, supported in a sling. Arterial pressure was monitored with a Statham P23DC pressure transducer and recorded on a Grass model 7 polygraph. A lead II electrocardiogram was monitored continuously and recorded. Bipolar composite electrograms, an atrial bipolar electrogram and a lead II electrocardiogram were recorded on a Honeywell model 1858 Visicorder filtered at 15 to 2,500 hertz. If the ventricular ectopic rate was greater than 10 beats/min, the animal was returned to its quarters and monitored 24 hours later. If the rate was 10 beats/min or less, the following procedure was used: $\mathrm{A}$ Grass model $\mathrm{SD}_{5}$ stimulator was used to deliver square wave impulses, $3 \mathrm{~ms}$ in duration, at a voltage twice the diastolic threshold for atrial or ventricular pacing $\left(S_{1}\right.$ stimuli). A Tektronix model 565 oscilloscope and differential amplifier were used to trigger the output of a Grass model S88 stimulator at the peak of the $\mathrm{R}$ wave of the lead II electrocardiogram. A Grass model S88 stimulator and SIU5 stimulus isolation unit delivered $3 \mathrm{~ms}$ square wave pulses $\left(\mathrm{S}_{2}\right.$ and $\mathrm{S}_{3}$ stimuli) at selected delays after the peak of the $R$ wave to the bipolar electrode located in the interventricular septum. $\mathrm{Di}$ astolic threshold was determined $200 \mathrm{~ms}$ after the peak of the $R$ wave. All subsequent premature stimuli delivered to the interventricular septum were 1.5 times diastolic threshold.

The effective refractory period of the left ventricular myocardium was determined using square wave pulses ( 1.5 times threshold, $3 \mathrm{~ms}$ in duration) and decreasing the $\mathrm{R}$ to $\mathrm{S}_{2}$ interval until a conducted beat was not generated. Activation times ( $Q-E G$ intervals), the delay from the $Q$ wave of the lead II electrocardiogram to the major positive spike of the normal zone or ischemic zone epicardial bipolar composite electrograms, were determined during atrial pacing at a rate of 175 beats/min. All electrophysiologic measurements were made from recordings performed at a paper speed of 100 to 400 $\mathrm{mm} / \mathrm{s}$.

Administration of disopyramide: Disopyramide phosphate was administered by a series of two stage intravenous infusions as described by Wagner. ${ }^{10}$ The values for apparent volume of distribution ( 2.01 liters $/ \mathrm{kg}$ ), alpha phase elimination constant (44.4 hour $^{-1}$ ), and beta phase elimination constant $\left(0.55\right.$ hour $\left.^{-1}\right)$ were obtained from earlier pharmacokinetic studies. ${ }^{11,12}$ The infusion protocol was designed to reach and maintain successive steady state disopyramide plasma levels of $1,2,3,4$, and $8 \mu \mathrm{g} / \mathrm{ml}$. An infusion of disopyramide at a rate of $23.3 \mathrm{mg} / \mathrm{kg}$ per hour for 4 minutes was followed by a second infusion of $1.09 \mathrm{mg} / \mathrm{kg}$ per hour designed to maintain plasma disopyramide concentrations of $1 \mu \mathrm{g} / \mathrm{ml}$. The infusion rate was increased to $24.4 \mathrm{mg} / \mathrm{kg}$ per hour for 4.0 minutes followed by an infusion at a rate of $2.18 \mathrm{mg} / \mathrm{kg}$ per hour to maintain plasma concentrations of $2 \mu \mathrm{g} / \mathrm{ml}$. The infusion rate was increased again to $24.4 \mathrm{mg} / \mathrm{kg}$ per hour for 4.8 minutes followed by an infusion at a rate of $3.28 \mathrm{mg} / \mathrm{kg}$ per hour to maintain plasma concentrations of $3 \mu \mathrm{g} / \mathrm{ml}$. To increase the steady state plasma concentrations to $4 \mu \mathrm{g} / \mathrm{ml}$, the infusion rate was increased to $24.4 \mathrm{mg} / \mathrm{kg}$ per hour for 5.3 minutes followed by an infusion at a rate of $4.37 \mathrm{mg} / \mathrm{kg}$ per hour to maintain steady state concentrations. Steady state plasma disopyramide concentrations of $8 \mu \mathrm{g} / \mathrm{ml}$ were achieved by increasing the infusion rate to $101.9 \mathrm{mg} / \mathrm{kg}$ per hour for 5 minutes followed by an infusion at a rate of $8.72 \mathrm{mg} / \mathrm{kg}$ per hour. A period of $20 \mathrm{~min}$ utes was allowed to pass at each steady state plasma concentration before electrophysiologic testing was initiated. Disopyramide phosphate was administered using a Harvard model 975 infusion pump.

Determination of plasma disopyramide concentration: Blood samples $(3 \mathrm{ml})$ were collected in $5 \mathrm{ml}$ tubes containing 500 units of sodium heparin. Plasma disopyramide concentrations were determined with the gas chromatographic method of Patterson et al. ${ }^{13}$ Plasma samples were taken just 
before and after electrophysiologic testing at each steady state plasma level. Plasma potassium concentrations were determined from these samples with use of flame spectrophotometry.

Determination of infarct size: The animals were anesthetized with sodium pentobarbital, $20 \mathrm{mg} / \mathrm{kg}$ intravenously. The heart was excised, rinsed briefly in cold water and sliced from apex to base into $1 \mathrm{~cm}$ thick sections. The slices were incubated in 0.2 percent triphenyltetrazolium in $0.1 \mathrm{M}$ phosphate buffer, pH 7.4, at $40^{\circ} \mathrm{C}$ for 15 minutes. Infarct size was determined gravimetrically and expressed as a percent of total left ventricular mass.

Materials: Disopyramide phosphate and p-chlorodisopyramide phosphate were obtained from the G.D. Searle Company. Triphenyltetrazolium was purchased from the Sigma Chemical Company. All other chemicals were reagent grade.

Statistical methods: Numerical values are expressed as the mean \pm standard error of the mean. Differences between groups were analyzed by analysis of variance.

\section{Results}

Rate-dependent conduction disorders: Two to 4 days after myocardial infarction, the ventricular ectopic rate had decreased to $3 \pm 1$ complexes/min, and the animals were entered into the study protocol. Composite bipolar electrodes were used to record left ventricular myocardial activation. Activation of ischemic myocardium was prolonged ( $82 \pm 13 \mathrm{~ms})$ compared with activation of normal myocardium $(49 \pm 11 \mathrm{~ms}$ ) (Table I). Left atrial pacing was used to increase sequentially the ventricular rate $t o 300$ beats/min or unlil the development of atrioventricular dissociation. As the ventricular rate increased, there was a significant increase in the duration of activation of ischemic myocardium whereas no change was seen in the duration of electrical activity in normal left ventricular myocardium (Table I). A further increase in the ventricular rate produced fractionation of the ischemic zone bipolar composite electrogram (Fig. 1).

Induction of ventricular tachycardia: Two to 4 days after myocardial infarction, programmed electrical stimulation was used to initiate reentrant rhythm in the conscious dogs. Premature ventricular stimuli were introduced during both normal sinus rhythm (cycle lengths 357 to $501 \mathrm{~ms}$ ) and atrial pacing (cycle lengths 284 to $454 \mathrm{~ms}$ ). No differences were observed between the duration or rate of ventricular tachycardia induced

\section{TABLE I}

Duration of Electrical Activation of Ventricular Myocardium 48 Hours After Myocardlal Infarction

\begin{tabular}{ccc}
\hline $\begin{array}{c}\text { Cycle Length } \\
\text { (ms) }\end{array}$ & \multicolumn{2}{c}{ Duration of Activation (ms) } \\
\cline { 2 - 3 } & Normal Zone & Ischemic Zone \\
\hline $430 \pm 23$ & $49 \pm 11$ & $82 \pm 13^{\dagger}$ \\
$253 \pm 12$ & $46 \pm 8$ & $106 \pm 19^{*}$ \\
\hline
\end{tabular}

- † Probability [p] values: * <0.05, compared with ischemic zone electrical activation duration at a cycle length of $430 \pm 23 \mathrm{~ms},{ }^{\dagger}<0.05$ compared with normal zone. in any one animal by single or double premature stimuli during either normal sinus rhythm or atrial pacing, and therefore the data are grouped in Table II. In three animals, sustained ventricular tachycardia lasting in excess of 2 minutes was observed. Four of eight episodes were self-terminating. Episodes of sustained ventricular tachycardia producing hypotension were terminated with single premature ventricular stimuli (Fig. 2). In one animal, ventricular tachycardia proceeded to ventricular fibrillation within 10 seconds of introduction of a single premature stimulus.

Electrophysiologic effects of steady state plasma disopyramide concentrations of $1 \mu \mathrm{g} / \mathrm{ml}$ : Disopyramide plasma concentrations of $1.02 \pm 0.02 \mu \mathrm{g} / \mathrm{ml}$ increased both the rate and duration of the induced ventricular tachycardia and duration of ischemic zone asynchronous electrical activity (Table II, Fig. 3 and 4). The interval during which ventricular tachycardia could be induced (induction period) also was increased. The critical coupling interval was increased for ventricular tachycardia induced by single $\left(S_{2}\right)$ or double $\left(S_{2}\right.$ and $\left.S_{3}\right)$ premature stimuli. Sustained ventricular tachycardia now could be induced in two animals in which only nonsustained ventricular tachycardia could be induced before administration of disopyramide. The changes occurred simultaneously with a decrease in the ventricular effective refractory period and a decrease in activation times of the ischemic myocardium (Table III). However, the cycle lengths at which Wenckebach-like conduction of ischemic potentials occurred
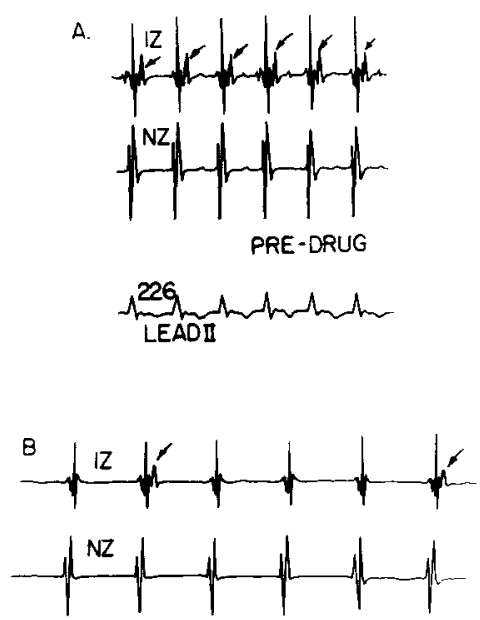

2.97 UG/ML DISOPYRAMIDE

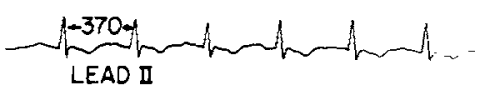

FIGURE 1. Conduction in ischemic myocardium-effect of disopyramide. A, before administration of disopyramide, atrial pacing decreases the ventricular cycle length to $226 \mathrm{~ms}$; at this cycle length, fractionation of ventricular activation occurs. Slightly shorter cycle lengths produced Wenckebach-like conduction of these ischemic potentials (not shown). B, at disopyramide plasma concentrations of 2.97 $\mu \mathrm{g} / \mathrm{ml}$, Wenckebach-like conduction (3:1) occurs at a cycle length of $370 \mathrm{~ms}$. Ischemic electrical potentials are marked by arrows. $1 \mathrm{Z}=$ ischemic zone; NZ = normal zone. 
TABLE ||

Electrophysiologic Variables

\begin{tabular}{|c|c|c|c|c|c|}
\hline \multirow{2}{*}{$\begin{array}{c}\text { Plasma } \\
\text { Disopyramide } \\
\text { Concentration } \\
(\mu \mathrm{g} / \mathrm{ml})\end{array}$} & \multirow{2}{*}{$\begin{array}{c}\text { Reentrant } \\
\text { Beats } \\
\text { (n) }\end{array}$} & \multirow{2}{*}{$\begin{array}{l}\text { Cycle Length } \\
\text { of Ventricular } \\
\text { Tachycardia } \\
\text { (ms) }\end{array}$} & \multirow{2}{*}{$\begin{array}{l}\text { Duration of } \\
\text { Asynchronous } \\
\text { Activity } \\
\text { (ms) }\end{array}$} & \multicolumn{2}{|c|}{$\begin{array}{c}\text { Induction } \\
\text { Period (ms) }\end{array}$} \\
\hline & & & & $\mathrm{S}_{2}$ & $\mathrm{~S}_{3}$ \\
\hline $\begin{array}{l}\text { (before drug } \\
\text { administration) }\end{array}$ & $6.2 \pm 0.8$ & $163 \pm 6$ & $1005 \pm 83$ & $25 \pm 2$ & $37 \pm 4$ \\
\hline $\begin{array}{l}1.02 \pm 0.02 \\
2.05 \pm 0.08 \\
2.99 \pm 0.03 \\
3.94 \pm 0.09 \\
7.69 \pm 0.18\end{array}$ & $\begin{array}{l}8.4 \pm 0.8^{*} \\
5.5 \pm 0.8^{*} \\
4.3 \pm 1.1^{*} \\
3.6 \pm 0.4^{\dagger} \\
0.6 \pm 0.5^{\dagger}\end{array}$ & $\begin{array}{l}155 \pm 2^{*} \\
193 \pm 8^{*} \\
218 \pm 14^{\dagger} \\
245 \pm 8^{\dagger} \\
315 \pm 10^{\dagger}\end{array}$ & $\begin{array}{c}1195 \pm 87^{*} \\
990 \pm 81 \\
968 \pm 123 \\
882 \pm 102^{*} \\
-\end{array}$ & $\begin{array}{l}42 \pm 4^{*} \\
24 \pm 6 \\
20 \pm 5 \\
16 \pm 5^{*}\end{array}$ & $\begin{array}{l}48 \pm 4^{*} \\
34 \pm 4 \\
26 \pm 7 \\
23 \pm 9^{*} \\
-\end{array}$ \\
\hline
\end{tabular}

${ }^{*} p<0.05,{ }^{\dagger} p<0.01$ compared with values before drug administration.

were not altered from the values before drug administration.

Electrophysiologic effects of increasing plasma disopyramide concentrations: Plasma disopyramide concentrations were increased sequentially to steady state concentrations of $2.05 \pm 0.08,2.99 \pm 0.03,3.94 \pm$ 0.09 and $7.69 \pm 0.18 \mu \mathrm{g} / \mathrm{ml}$. These increases produced a concentration-dependent increase in the cycle length of ventricular tachycardia without shortening the duration of the tachycardia until plasma levels of $7.69 \pm$ $0.18 \mu \mathrm{g} / \mathrm{ml}$ were attained (Table II, Fig. 3 and 4). The induction periods for the premature stimuli $S_{2}$ and $S_{3}$ were reduced sequentially by increasing plasma disopyramide concentrations, although ventricular tachycardia could be induced in all animals at plasma disopyramide concentrations of $3.94 \pm 0.09 \mu \mathrm{g} / \mathrm{ml}$. The slowing of the rate of tachycardia occurred simultaneously with the depression of cardiac conduction, as reflected in the concentration-dependent increase in the cycle length of the ventricular arrhythmia and the increase in the activation times of normal and ischemic myocardium. Increasing plasma disopyramide concentrations also produced sequential increases in ventricular refractoriness (Table III).

Disopyramide plasma concentrations of $7.69 \pm 0.18$ $\mu \mathrm{g} / \mathrm{ml}$ were necessary to suppress completely the induction of ventricular tachycardia. In several instances, single or double reentrant beats were seen (Fig. 3), but longer runs of ventricular tachycardia could not be induced. The elevated disopyramide plasma concentration produced considerable conduction delay in normal and ischemic myocardium and produced a $23 \mathrm{~ms}$ increase in the effective refractory period of the normal left ventricular myocardium (Table III).

Plasma potassium concentrations: Plasma potassium concentrations were determined before and after electrophysiologic testing at each steady state plasma disopyramide concentration as well as before adminis-
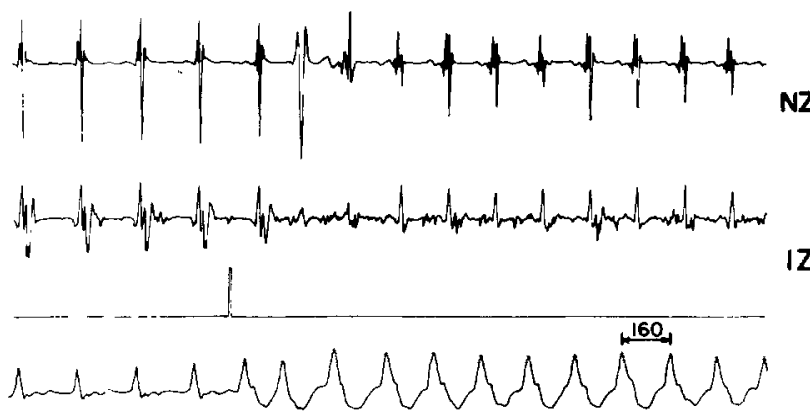

17
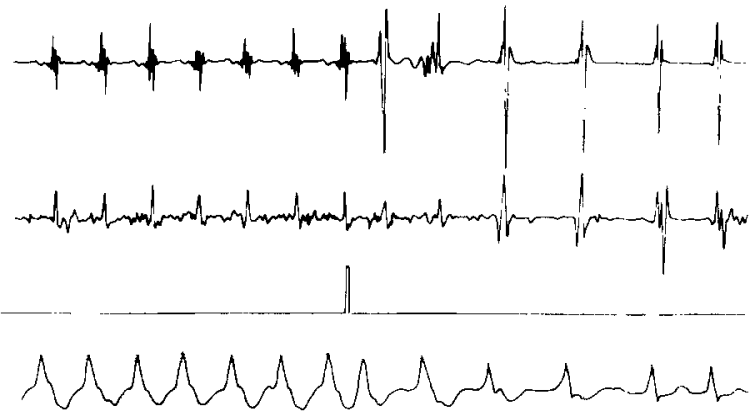

II

A.

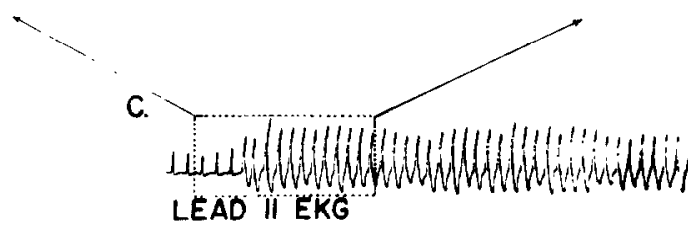

B.

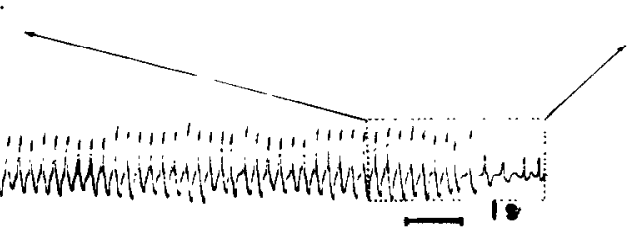

FICURE 2. Sustained ventricular tachycardia. A, sustained ventricular tachycardia is induced by a single premature stimulus. B, ventricular tachycardia is terminated by a single premature impulse because of hypotension. Premature stimuli are marked by narrow rectangles in $\mathbf{A}$ and $B$. Electrical activation of normal myocardium (NZ) remains discrete during ventricular tachycardia although ischemic zone (IZ) activation was continuous. Activation of normal and ischemic myocardium was measured with bipolar composite electrodes. EKG = electrocardiogram. 
A. PRE - DRUG

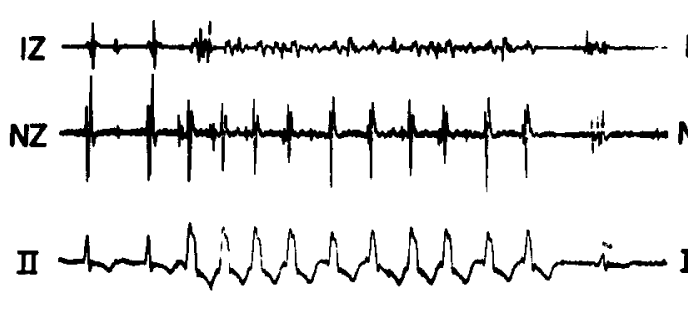

B.1.02 UG/ML

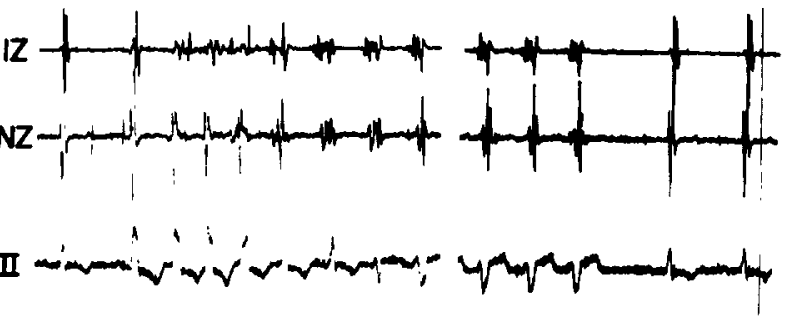

D.7.72 UG/ML
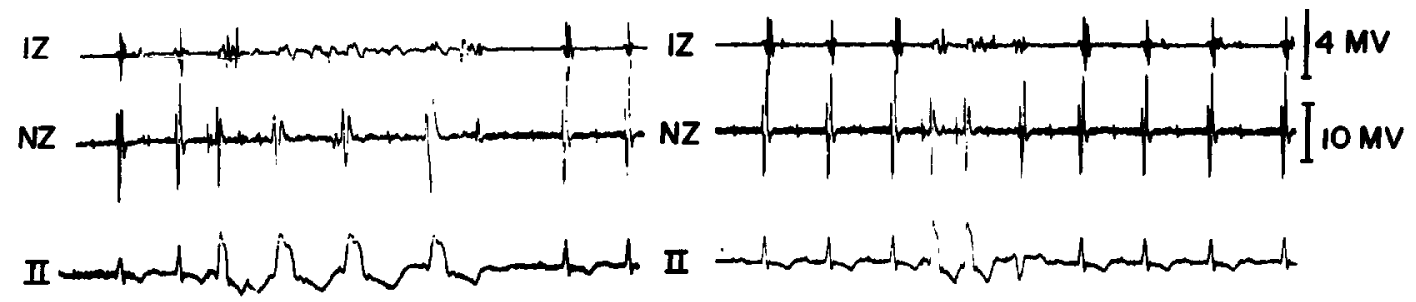

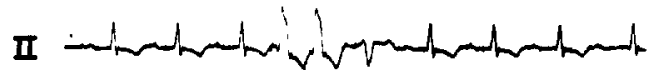

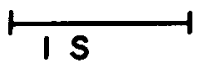

FICURE 3. Induced ventricular tachycardia-effect of disopyramide. A, before administration of disopyramide, a single premature stimulus elicits a nine beat ventricular tachycardia with a cycle length of $225 \mathrm{~ms}$. B, at a plasma disopyramide concentration of $1.02 \mu \mathrm{g} / \mathrm{ml}$, a single premature stimulus produces sustained ventricular tachycardia at a cycle length of $216 \mathrm{~ms}$. The ventricular tachycardia was sustained for 2 minutes and 45 seconds, after which spontaneous slowing and termination were seen. $\mathbf{C}$, at a plasma disopyramide concentration of $3.97 \mu \mathrm{g} / \mathrm{ml}$, a single premature stimulus elicits a ventricular tachycardia of three beats having a cycle length of $419 \mathrm{~ms}$. D, at a plasma disopyramide concentration of $7.72 \mu \mathrm{g} / \mathrm{ml}$, two premature stimuli produce a single reentrant beat. Activation of normal myocardium (NZ) remained discrete in the composite electrogram whereas ischemic zone activation (IZ) was continuous during ventricular tachycardia.

tration of disopyramide. Before administration of disopyramide, the plasma potassium concentration was $3.8 \pm 0.1 \mathrm{mEq} /$ liter and did not change significantly throughout the course of the experiment.

Infarct size: Occlusion of the left anterior descending coronary artery for a period of 90 minutes followed by reperfusion of the ischemic myocardium produced infarct masses of 3.2 to $34.6 \mathrm{~g}$, representing 3.0 to 34.0

\section{TABLE III}

Effective Refractory Periods and Changes in Q-EG Interval (mean values \pm standard error of the mean)

\begin{tabular}{|c|c|c|c|}
\hline \multirow{2}{*}{$\begin{array}{c}\text { Plasma } \\
\text { Disopyramide } \\
\text { Concentration } \\
(\mu \mathrm{g} / \mathrm{ml})\end{array}$} & \multirow{2}{*}{$\begin{array}{l}\text { Effective } \\
\text { Refractory } \\
\text { Periods } \\
\text { (ms) }\end{array}$} & \multicolumn{2}{|c|}{$\Delta Q-E G(m s)$} \\
\hline & & Normal Zone & Ischemic Zone \\
\hline $\begin{array}{l}\text { (before drug } \\
\text { administration) }\end{array}$ & $142 \pm 8$ & $\ldots$ & $\cdots$ \\
\hline $\begin{array}{l}1.02 \pm 0.02 \\
2.05 \pm 0.08 \\
2.99 \pm 0.03 \\
3.94 \pm 0.09 \\
7.69 \pm 0.18\end{array}$ & $\begin{array}{l}138 \pm 9^{*} \\
146 \pm 8^{*} \\
147 \pm 9^{*} \\
148 \pm 10^{*} \\
165 \pm 3^{\dagger}\end{array}$ & $\begin{array}{c}-0.2 \pm 0.3 \\
0.2 \pm 0.3 \\
0.6 \pm 0.2^{*} \\
1.9 \pm 0.6^{*} \\
4.6 \pm 0.7^{*}\end{array}$ & $\begin{array}{r}-3.9 \pm 1.6^{*} \\
4.2 \pm 0.9^{*} \\
7.6 \pm 1.2^{*} \\
9.8 \pm 0.9^{\dagger} \\
18.5 \pm 2.9^{\dagger}\end{array}$ \\
\hline
\end{tabular}

* $p<0.05,{ }^{\dagger} p<0.01$ compared with values before drug administration.

Q-EG = interval from the initiation of the Q wave of lead II to the major deflection in the bipolar electrogram; $\triangle \mathrm{Q}-E G=$ change from the value obtained before drug administration (value before drug administration $=0$ ). percent of the left ventricular mass (mean $19.4 \pm 3.8$ percent). The infarcts were located subendocardially and did not extend to the epicardial surface.

\section{Discussion}

Improved activation in ischemic myocardium and induction of reentrant tachyarrhythmia with subtherapeutic concentrations: Steady state plasma disopyramide concentrations of $1.02 \pm 0.02 \mu \mathrm{g} / \mathrm{ml}$ increased the duration and decreased the cycle length of reentrant ventricular tachycardia. This action is not unique to disopyramide: El-Sherif and Lazzara ${ }^{14}$ have shown verapamil to improve conduction in ischemic canine myocardium by improving depressed phase 0 maximal upstroke velocity of Purkinje fibers. In addition, verapamil has been shown to decrease the cycle length of reentrant ventricular tachycardia and to increase the incidence of ventricular fibrillation in dogs 3 to 5 days after myocardial ischemic injury. ${ }^{15}$ Although there are few similarities in the mechanisms of action of disopyramide and verapamil, these data suggest that improvement of depressed conduction in ischemic myocardium may result in increased rates of ventricular tachycardia and an increased incidence of ventricular fibrillation.

Reddy and co-workers ${ }^{16,17}$ demonstrated that subtherapeutic concentrations of procainamide facilitated the induction of tachyarrhythmia in human subjects. Nonsustained ventricular tachycardia became sustained 

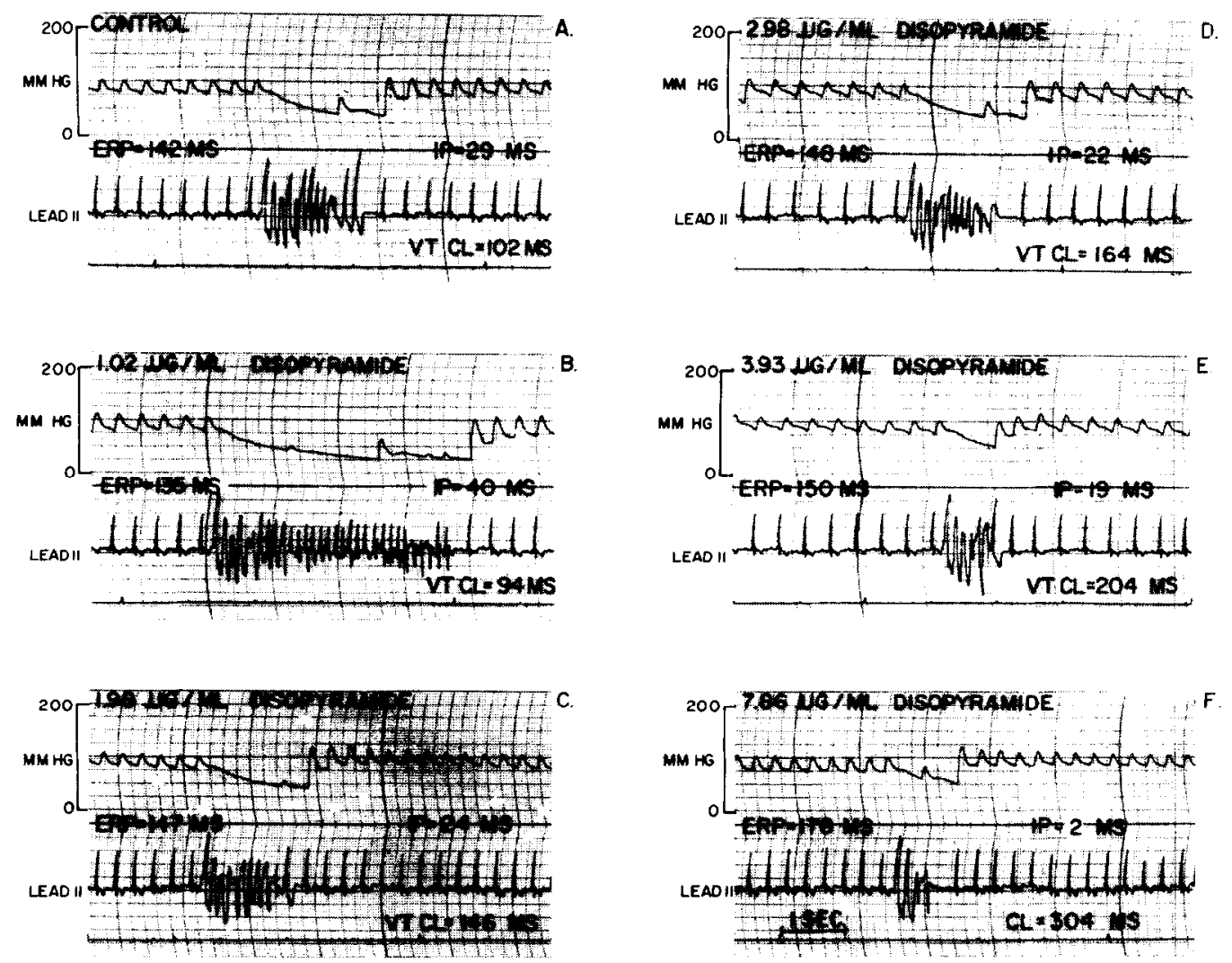

FICURE 4. Induced ventricular tachycardia-effect of disopyramide. Lead II electrocardiograms and arterial blood pressure tracings are shown before and after administration of dlsopyramide. A, double premature stimull produce a 10 beat run of ventrlcular tachycardia with a cycle length (VT CL) of $102 \mathrm{~ms}$. B, at a plasma disopyramide concentration of $1.02 \mu \mathrm{g} / \mathrm{ml}$, the tachycardia increases to 20 beats at a cycle length of $94 \mathrm{~ms}$ after two premature stimuli. The period of induction of tachycardia (IP) increases from 29 to $40 \mathrm{~ms}$ whereas the effective refractory periods (ERP) is reduced from 142 to $135 \mathrm{~ms}$. C,D,E, increasing plasma disopyramide concentrations of $1.98,2.98$ and $3.93 \mu \mathrm{g} / \mathrm{ml}$ produce lengthening of the cycle lengths of the induced ventricular tachycardia to 146,164 and $204 \mathrm{~ms}$, respectively, and decrease the duration of the ventricular tachycardia. Only modest reductions of the induction periods and small increases in the effective refractory periods are seen. $F$, two premature stimuli produce a reentrant couplet with a cycle length of $304 \mathrm{~ms}$. The induction period of this couplet was $2 \mathrm{~ms}$.

after administration of procainamide, and reentrant rhythms could be induced only after its administration. Horowitz et al. ${ }^{18}$ observed similar results when they administered procainamide to survivors of apparent sudden coronary death whose nonsustained reentrant rhythm became sustained ventricular tachycardia. They reported that a decrease in conduction velocity occurred simultaneously with facilitated reentry and postulated that procainamide facilitated reentry by slowing conduction velocity to a greater degree than it increased ventricular refractoriness. Larger doses of procainamide prevented the induction of reentrant cardiac rhythms. In our study with disopyramide, depression of cardiac conduction was not observed at the time when the periods required for induction of reentrant rhythms were increased; rather, there was an improvement in myocardial activation in ischemic myocardium.

The electrophysiologic actions of subtherapeutic concentrations of disopyramide have not previously been investigated. However, "therapeutic concentrations" of disopyramide have been shown to produce decreases in the rate of phase 0 depolarization of canine Purkinje fihers ${ }^{19-21}$ and in myocardial conduction ve- locity. ${ }^{22}$ Improvement in cardiac conduction has not been reported. The direct depressant actions of disopyramide may predominate at higher concentrations whereas at lower concentrations the drug might act indirectly through an antagonism of muscarinic cholinergic receptors. $22-25$

Increased activation time and ventricular refractoriness with high plasma concentrations: Increasing plasma concentrations of disopyramide produced progressive increases in ventricular activation times and in ventricular refractoriness in normal and ischemic myocardium. The increases in activation times of ischemic myocardium were greater than those in normal myocardium. Slowing of the cardiac impulse through ventricular myocardium comprising the reentry circuit is a possible factor involved in the slowing of the ventricular tachycardia after administration of disopyramide, although the role of increased myocardial refractoriness is unknown.

Increasing steady state disopyramide plasma concentrations slightly reduced the periods required for induction of ventricular tachycardia. Reduction of this critical interval may be somewhat beneficial, but com- 
plete prevention of the induction of ventricular tachycardia may be necessary for prevention of sudden coronary death. Ruskin and Garan ${ }^{26}$ demonstrated that antiarrhythmic drug therapy that renders ventricular tachycardia noninducible by programmed cardiac stimulation constitutes effective prophylaxis against spontaneous recurrent sustained ventricular tachycardia in the majority of patients studied. Josephson et al. ${ }^{27}$ showed that failure to maintain plasma concentrations of antiarrhythmic drugs at levels previously shown to be effective in preventing the induction of sustained ventricular tachycardia can lead to the recurrence of sustained ventricular tachycardia or sudden coronary death. The 25 to 40 percent reduction in the period required for induction of sustained tachycardia, seen in our study at plasma disopyramide concentrations of $3.94 \pm 0.09 \mu \mathrm{g} / \mathrm{ml}$, may be ineffective in preventing sudden coronary death because only concentrations of $7.69 \pm 0.18 \mu \mathrm{g} / \mathrm{ml}$ prevented electrical induction of ventricular tachyarrhythmia (Table II).

It is not surprising that high plasma disopyramide concentrations are needed for suppression of induction of ventricular tachycardia. Benditt et al. ${ }^{28}$ reported that disopyramide plasma concentrations that prevented the induction of ventricular tachycardia in human subjects were in excess of $3 \mu \mathrm{g} / \mathrm{ml}$ (mean nearly $5 \mu \mathrm{g} / \mathrm{ml}$ ). Similarly, procainamide's effectiveness was reported to require plasma concentrations in excess of $9 \mu \mathrm{g} / \mathrm{ml}$ whereas quinidine plasma concentrations necessary for prevention of induction of ventricular tachycardia were in excess of $3 \mu \mathrm{g} / \mathrm{ml}^{25-27}$ Thus, the plasma concentrations of antiarrhythmic agents necessary for prevention of sudden coronary death may be higher than currently accepted "therapeutic concentrations." However the "high" plasma concentrations of antiarrhythmic drugs may prove to have deleterious actions on cardiac electrophysiology and myocardial function. ${ }^{29-31}$

Clinical implications: The majority of cardiac deaths are sudden and most likely due to a "primary" arrhythmic event most often characterized by ventricular fibrillation. Endeavors to prevent sudden coronary death with pharmacologic means have resulted in numerous reports in which drugs have been claimed to be "effective" solely because of their ability to reduce the frequency of premature ventricular complexes. This study, although conducted in the experimental animal, might provide some important insights into an understanding of why there often exists a lack of a predictable relation between the ability to suppress chronic asymptomatic complex ventricular arrhythmia and ventricular fibrillation or sudden coronary death. As demonstrated in the canine model using programmed cardiac stimulation in the presence of latent electrical instability, concentrations ( 2 to $4 \mu \mathrm{g} / \mathrm{ml}$ ) of disopyramide known to reduce or prevent complex premature depolarizations were unable to prevent the induction of sustained reentrant ventricular tachyarrhythmia. The suggestion that recurrent episodes of ventricular tachycardia or ventricular fibrillation, or both, might be prevented by relatively high plasma concentrations of disopyramide has important implications with respect to future clinical trials designed to explore the prophylactic use of this drug in the patient at risk of sudden coronary death. A beneficial effect might not be realized if such trials follow current "therapeutic" guidelines in suggesting maintenance of plasma concentrations of 2 to $4 \mu \mathrm{g} / \mathrm{ml}$. However, the negative inotropic effect of disopyramide may preclude the use of higher dosage regimens in patients with compromised left ventricular function.

We are entering an era in which the pharmacologic prevention of sudden coronary death may soon become a reality. The task of identifying the proper agent or agents will not be a simple one; a single approach to the prevention of ventricular fibrillation is probably not attainable because the arrhythmia probably results from the interplay of many mechanisms, the most important of which is an acute or chronic state of electrical instability. The animal model used in our study has the advantage over previous models of more closely representing the clinical state associated with sudden coronary death. It may be useful in exploring the pathophysiologic processes that render the myocardium vulnerable to ventricular fibrillation and in studying how pharmacologic agents act to prevent a fatal electrical event.

\section{References}

1. Wellens HJ, Schullenburg RM, Durrler D. Electrical stimulation of the heart in patients with ventricular tachycardia. Circulation 1972;46:216-26.

2. Mason JW, Winkle RA. Electrode-catheter arrhythmia induction in the selection and assessment of antiarrhythmic drug therapy for recurrent ventricular tachycardia. Am J Cardiol 1977:40:579 85.

3. Wellens HJJ, Duren DR, Lie KI. Observations on mechanisms of ventricular tachycardia in man. Circulation 1976;54:237-44.

4. Splelman SR, Farshidl A, Horowitz LN, Josephson ME. Ventricular fibrillation during programmed ventricular stimulation: incidence and clinical implications. Am J Cardiol 1978;42:913-8.

5. Josephson ME, Horowitz LN, Farshidi A, Splelman SR, Michelson EL, Greenspan AM. Sustained ventricular tachycardia: evidence for protected localized reentry. Am J Cardiol 1978;42:416-24.

6. Lazzara R, EI-Sherif N, Hope RR, Scherlag BJ. Ventricular ar- rhythmias and electrophysiological consequences of myocardial ischemia and infarction. Circ Res 1978;42:740-8.

7. Harris AS. Delayed development of ventricular ectopic rhythms following experimental coronary. occlusion. Circulation 1950;1: 1318-28.

8. Karagueuzian HS, Fenogllo JJ, Weiss MB, Wit AL. Protracted ventricular tachycardia induced by premature stimulation of the canine heart after coronary artery occlusion and reperfusion. Circ Res 1979;44:833-46.

9. El-Sherif N, Scherlag BJ, Lazzara R, Hope RR. Reentrant ventricular arrhythmias in the late myocardial infarction period. 4. Mechanism of action of lidocaine. Circulation 1977;56:395402.

10. Wagner J. Fundamentals of Clinical Pharmacokinetics. Hamilton, IL: Drug Intelligence Publications, 1975:91-7.

11. Ranney RE, Dean RR, Karlm A, Radzialowskl FM. Disopyramide 
phosphate: pharmacokinetics and pharmacological relationships of a new antiarrhythmic agent. Arch Int Pharmacodyn Ther 1972;191:162-88.

12. Karim A, Kook C, Novotney RL, Zagarella J, Campion J. Pharmacokinetics and steady state myocardial uptake of disopyramide. Drug Metab Dispos 1978;6:338-45

13. Patterson E, Stetson P, Lucchesi BR. Disopyramide plasma and myocardial tissue concentrations as they relate to antiarrhythmic activity. J Cardiovasc Pharmacol 1979;1:541-50.

14. El-Sherlf $\mathbf{N}$, Lazzara R. Re-entrant ventricular arrhythmias in the late myocardial infarction period. 7 . Effect of verapamil and D-600 and the role of the "slow channel." Circulation 1979;60:60515.

15. Glassman RD, Davis JC, Wit AL. Effects of antiarrhythmic drugs on sustained ventricular tachycardia induced by a premature stimulus in dogs after coronary artery occulsion and reperfusion (abstr). Fed Proc 1978;37:730A

16. Reddy CP, Damato AN, Akhtar M, Dhatt MS, Gomes JAC, Calon AH. Effect of procainamide on reentry within the His-Purkinje system in man. Am J Cardiol 1977;4:957-64.

17. Reddy CP, Lynch $M$. Abolition and modification of re-entry within the His-Purkinje system by procainamide in man. Circulation 1978;58:1010-22.

18. Horowltz LN, Josephson ME, Farshidl A, Spleiman SR, Michelson EL, Greenspan AM. Recurrent sustained ventricular tachycardia. 3. Role of the electrophysiologic study in selection of antiarrhythmic regimens. Circulation 1978;58:968-97.

19. Danilo P, Hordof AJ, Rosen MR. Effects of disopyramide on electrophysiologic properties of canine cardiac Purkinje fibers. J Pharmacol Exp Ther 1977;201:701-10.

20. Kus T, Sasyniuk BI. The electrophysiological effects of disopyramide phosphate on canine ventricular muscle and Purkinje fibers in normal and low potassium. Can J Physiol Pharmacol 1978;55: 139-49.
21. Kus T, Sasyniuk BI. Electrophysiological effects of disopyramide phosphate on canine ventricular muscle and Purkinje fibers. Circ Res 1975;37:844-54.

22. Kus T, Sasyniuk BI. Effects of disopyramide phosphate on ventricular arrhythmias in experimental myocardial infarction. $J$ Pharmacol Exp Ther 1974;196:665-75.

23. Mirro MJ, Watanabe AM, Bally JC. Anticholinergic effects of quinidine and disopyramide on canine cardiac Purkinje fibers (abstr). Clin Res 1979;27:189A.

24. Bally JC, Watanabe AM, Besch HR, Lathrop DA. Acetylcholine antagonism of the electrophysiological effects of isoproterenol on canine Purkinje fibers. Circulation 1979;44:378-83.

25. Gadsby DC, Wit AL, Cranefield PF. The effects of acetylcholine on the electrical activity of canine cardiac Purkinje fibers. Circ Res 1978;43:29-35.

26. Ruskin JN, Garan H. Chronic electrophysiologic testing in patients with recurrent sustained ventricular tachycardia (abstr). Am J Cardiol 1979;43:400.

27. Josephson ME, Horowitz LN. Electrophysiologic approach to therapy of recurrent sustained ventricular tachycardia. Am $J$ Cardiol 1979;43:631-42.

28. Benditt DG, Pritchett ELC, Wallace AG, Gallagher JJ. Recurrent ventricular tachycardia in man: evaluation of disopyramide therapy by intracardiac electrical stimulation. Eur J Cardiol 1979;9: 225-76.

29. Meltzer RS, Robert EW, McMorrow M, Martln RP. Atypical ventricular tachycardia as a manifestation of disopyramide toxicity. Am J Cardiol 1978;42:1049-53.

30. Selzer A, Wray HW. Quinidine syncope: paroxysmal ventricular fibrillation occurring during treatment of chronic atrial arrhythmias. Circulation 1964; 30:17-23.

31. El-Sherif N. Electrophysiologic basis of procainamide therapeutic and toxic effects on ischemia-related ventricular arrhythmias (abstr). Am J Cardiol 1979;43:429. 